\title{
GALLIUM CONCENTRATION OPTIMISATION OF GALLIUM DOPED ZINC OXIDE FOR IMPROVEMENT OF OPTICAL PROPERTIES
}

\author{
A. Spustaka*, M. Senko, D. Millers, I. Bite, \\ K. Smits, V. Vitola \\ Institute of Solid State Physics, University of Latvia \\ 8 Kengaraga Str., Riga LV-1063, LATVIA \\ *e-mail: agnese.spustaka@cfi.lu.Iv
}

The near-band luminescence of doped $\mathrm{ZnO}$ is promising for advanced scintillators; however, the dopant type and concentration effects require a detailed study. Undoped and Ga-doped $\mathrm{ZnO}$ nanopowders were prepared by a microwave-assisted solvothermal method and the gallium concentration effect on luminescence properties was studied. The near-band luminescence peak position dependence on gallium concentration was observed. Near-band luminescence intensity versus defect luminescence intensity ratio was explored for different gallium concentrations and the optimal value was determined. Samples were prepared with dopant concentrations between 0.2 and 1.5 at $\%$, XRD analysis confirmed that samples contained only zinc oxide hexagonal wurtzite phase. The results of the research showed that $\mathrm{ZnO}$ :Ga containing 0.9 at.\% gallium was promising for scintillators.

Keywords: Luminescence, microwave-assisted solvothermal synthesis, optimised concentration, scintillator, $\mathrm{ZnO}: \mathrm{Ga}$.

\section{INTRODUCTION}

Zinc oxide $(\mathrm{ZnO})$ is a semiconductor material owning a wide band gap $(\sim 3.4 \mathrm{eV})$ and high exciton binding energy $(\sim 60 \mathrm{meV})$, which provides the possibility of observing highly efficient exitonic luminescence even at room temperatures [1]. The applications of zinc oxide are very wide - it is well-known as green, blue-ultraviolet and white-light emitting material, applicable for optoelectronic devices and gas sensors, 
catalysts as well as transparent electroconductive windows for solar cells, and many others [2]-[6].

One of the prospective applications is radiation detectors - devices that can detect electromagnetic as well as corpuscular ionizing radiation [7]. Radiation detectors are used in medicine, for example, during positron emission tomography and computer tomography [8], [9]. Moreover, for security and quality control, radiation detectors are used in manufacturing as well as there are other technological applications.

Sharp interest is related to the search for materials applicable for fast operating scintillators. Scintillators are materials for conversion of ionizing radiation photon energy to the light pulse. Thus, scintillators can detect a single ionizing radiation photon or a single charged particle. The ideal scintillator has high stopping power, fast scintillation response, high efficiency for ionizing radiation conversion to light photons, great physical and chemical stability, as well as high radiation hardness. The stopping power of $\mathrm{ZnO}$ is good due to large atomic mass of $\mathrm{Zn}$. In turn, the scintillation yield is up to 15000 photons $/ \mathrm{MeV}$ [10], scintillation decay time is below $1 \mathrm{~ns}$ $[10]$ and $Y$-rays do not create new defects in $\mathrm{ZnO}$ crystalline lattice [1]. Therefore, $\mathrm{ZnO}$ is a very promising material for advanced scintillators. The two main emission bands in the spectrum of $\mathrm{ZnO}$ are the near-band luminescence (NBL) in the near UV range and the defect luminescence band in the visible range. The NBL shows sub-nanosecond decay, whereas defect luminescence decay is within microseconds [11]. The main challenge for fast response scintillators is slow decaying defect luminescence. Therefore, for scintillators it is necessary to have $\mathrm{ZnO}$ with intensive NBL and low intensity defect luminescence. The doping of $\mathrm{ZnO}$ could suppress the defect luminescence [12], [13]; therefore, the study of doped $\mathrm{ZnO}$ is of interest.

There are a large number of reports about undoped zinc oxide; however, the luminescence of $\mathrm{ZnO}$ doped with gallium, indium and other dopants is yet to be explored [13]. Doped $\mathrm{ZnO}$ powder is a promising material for its usability in producing transparent ceramics with excellent properties for scintillators [14].

Incorporation of dopant, grain size and grain agglomeration of $\mathrm{ZnO}$ depends on a synthesis method as well as on chemicals used. Many methods were developed for $\mathrm{ZnO}$ synthesis - precipitation, sol-gel, solvothermal, hydrothermal and microwaveassisted solvo- or hydrothermal methods, etc. [15]-[17]. Recently, due to the control of sample morphology and size, temperature gradient versatility, relative simplicity and low reaction times, as well as environmental friendliness, microwave-assisted methods have become more commonly used [18]. On the other hand, incorporation of dopant in $\mathrm{ZnO}$ is synthesis dependent and, thus, there is interest in finding the optimal concentration of dopant for each synthesis method.

In the present paper, undoped and Ga-doped zinc oxide were prepared by a microwave-assisted solvothermal (MWST) synthesis technique. The effect of Ga concentration on crystallization, morphology and luminescence properties of $\mathrm{ZnO}$ was studied. The optimal gallium concentration with the most efficient NBL and relatively low intensity of defect luminescence was found. 


\subsection{Materials}

Zinc acetate $\left(\mathrm{Zn}\left(\mathrm{CH}_{3} \mathrm{COO}\right)_{2}\right.$, anhydrous, purity 99.9+\%; Alfa Aesar) and sodium hydroxide $(\mathrm{NaOH}$, purity $\geq 98 \%$; Sigma Aldrich) were used as the main precursors for $\mathrm{ZnO}$ synthesis; gallium trichloride $\left(\mathrm{GaCl}_{3}\right.$, purity $99.999 \%$; Alfa Aesar) was used as a dopant source and ethanol
( $\mathrm{C}_{2} \mathrm{H}_{5} \mathrm{OH}, 96 \%$; Ltd. Jaunpagasts Plus $)$ - as a solvent. Methanol $\left(\mathrm{CH}_{3} \mathrm{OH}\right.$, purity $\geq 99.8$ $\%$; Sigma Aldrich) was used for removal of synthesis reaction residue. Analytical grade chemicals were used without any further purification and were used as received.

\subsection{Synthesis of Undoped and Ga-doped ZnO Nanomaterials}

The undoped and Ga-doped $\mathrm{ZnO}$ nanopowders were synthesized by using a microwave-assisted solvothermal method (MWST). The samples of Ga-doped $\mathrm{ZnO}$ nanopowders were prepared with eight different concentrations (0-1.5 at.\%) of Ga. The MWST reaction was performed in a Milestone synthWAVE microwave reactor in an inert atmosphere $\left(\mathrm{N}_{2}, 99.999 \%\right)$. The system was operated at $2.45 \mathrm{GHz}$ frequency with power ranging from 0 to $100 \%$ of full power $(1.5 \mathrm{~kW})$.

In this synthesis route, the three precursor solutions were prepared by separately dissolving $\mathrm{Zn}\left(\mathrm{CH}_{3} \mathrm{COO}\right)_{2}$ in ethanol (0.3 $\mathrm{M}), \mathrm{GaCl}_{3}$ in ethanol $(0.5 \mathrm{M})$ and $\mathrm{NaOH}$ in ethanol $(0.6 \mathrm{M})$ at $80{ }^{\circ} \mathrm{C}$ under a constant stirring speed. After all the starting materials were dissolved completely, an appropriate amount of gallium ion solution was added to the $20 \mathrm{~mL}$ of zinc ion solution under a constant stirring speed. The solution was stirred for $15 \mathrm{~min}$ and after that 20 $\mathrm{mL}$ of $\mathrm{NaOH}$ solution was slowly added to the metal ion solution under a constant stirring speed. The resulting reaction mixture was stirred for $10 \mathrm{~min}$ and a milky white reaction mixture was obtained. After stirring, the reaction mixture was poured into a $70 \mathrm{~mL}$ PTFE vial, which was then placed in a Milestone synthWAVE reactor vessel. Undoped $\mathrm{ZnO}$ was prepared in the same way without adding a gallium ion solution.

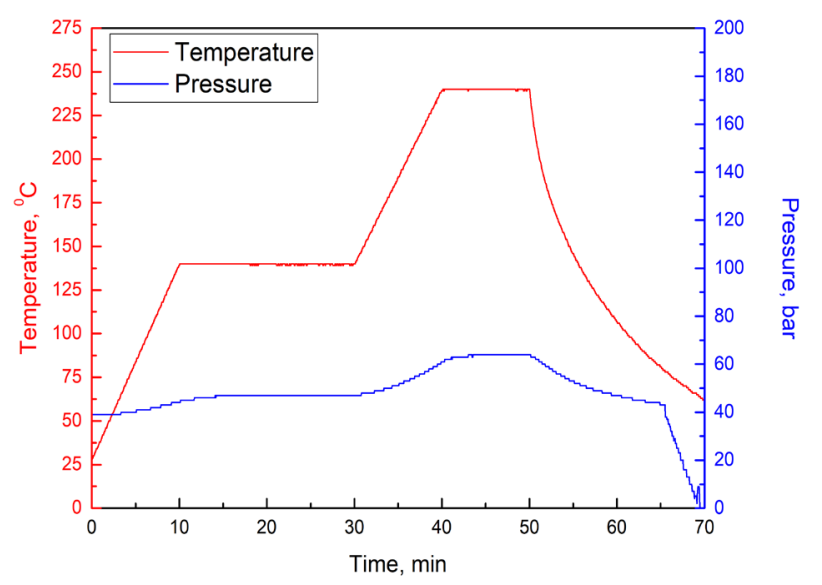

Fig. 1. Profile of MWST synthesis parameters for $\mathrm{ZnO}$ nanoparticle preparation. 
As shown in Fig. 1, the two-stage synthesis was used to obtain undoped and Gadoped $\mathrm{ZnO}$. During the synthesis, at the first stage microwave heating ramp was set to be $10{ }^{\circ} \mathrm{C} / \mathrm{min}$ with the target temperature of $140{ }^{\circ} \mathrm{C}$. At the target temperature, the reaction mixture was irradiated with microwaves for 30 minutes to proceed the complete exchange reaction between precursors, resulting in formation of $\mathrm{Zn}(\mathrm{OH})_{2}$. The starting pressure was set to be 40 bar. The pressure gradually increased by the growing temperature and the increasing amount of gases produced as the reaction by-products. During the second stage, the

\subsection{Characterisation Techniques}

Crystallinity of undoped and galliumdoped zinc oxide samples were characterised by X-ray powder diffraction (XRD) using a Rigaku MiniFlex 600 X-ray diffractometer. $\mathrm{Cu} \mathrm{K} \alpha$ radiation was used by setting the cathode voltage to $40 \mathrm{kV}$ and current to $15 \mathrm{~mA}$. The morphology of samples was characterised by scanning electron microscopy (SEM) using a SEM Helios operated at $5 \mathrm{kV}$. Before the examination, the samples were coated with a thin gold layer. temperature of $240{ }^{\circ} \mathrm{C}$ was achieved in 10 minutes and further the irradiation was continued for 10 minutes. Under these conditions, thermal decomposition of $\mathrm{Zn}(\mathrm{OH})_{2}$ was undergoing. Subsequently, the reaction mixture was naturally cooled down to room temperature. The nanoparticles of $\mathrm{ZnO}$ in the resulting sol were separated from the solvent by centrifugation and subsequent washing for 5 times with $20 \mathrm{~mL}$ of methanol for 15 minutes. The synthesis of undoped $\mathrm{ZnO}$ and $\mathrm{ZnO}: \mathrm{Ga}$ resulted in white and pastel blue (due to the gallium presence in the sample) coloured powders accordingly.

Photoluminescence (PL) spectral measurements were conducted using a Horiba iHR320 monochromator with $150 \mathrm{l} / \mathrm{mm}$ diffraction grating and a blaze wavelength of $500 \mathrm{~nm}$. The monochromator was coupled with an Andor DV420A-BU2 CCD camera. Photoluminescence was excited with a CryLas Nd:YAG laser (266 nm); spot size was approximately $3 \mathrm{~mm}$ in diameter, laser impulse duration was less than $2 \mathrm{~ns}$, max repetition rate was $5 \mathrm{kHz}$ with max output power of $0.3 \mu \mathrm{J}$.

\section{RESULTS AND DISCUSSION}

\subsection{X-Ray Diffraction Analysis}

X-ray powder diffraction spectra (Fig. 2) show that all peaks of all samples correspond to the hexagonal wurtzite structure. XRD data confirm that no gallium compound impurities are present in samples, meaning that gallium was incorporated in $\mathrm{ZnO}$ crystal lattice. Sharpness and relatively high intensity of XRD patterns indicated high crystallinity of powders. Gadoped $\mathrm{ZnO}$ has wider peaks than $\mathrm{ZnO}$ and it can take place if $\mathrm{ZnO}$ : Ga crystallites are smaller than that for $\mathrm{ZnO}$. A similar impact can be due to larger concentration of defects in $\mathrm{ZnO}$ : Ga crystallites. It is known that irradiating material with microwaves produces a greater level of crystallinity than conventional methods, such as wet synthesis [19]. For average crystallite size determination, Debye-Scherrer equation (1) was used:

$$
D=\frac{0.9 \lambda}{\beta \cos \theta},
$$


where $\lambda$-X-ray wavelength, $\beta$ - FWHM, Bragg diffraction angle.

Grain crystallite sizes of $\mathrm{ZnO}: \mathrm{Ga}$ samples were found to be in the range of 22-30 nm, with an average being $26 \mathrm{~nm}$. The sizes of crystallites of undoped $\mathrm{ZnO}$ were found to be in the range of 39-41 $\mathrm{nm}$. Therefore, wider XRD lines for $\mathrm{ZnO}: \mathrm{Ga}$ are due to smaller crystallites.

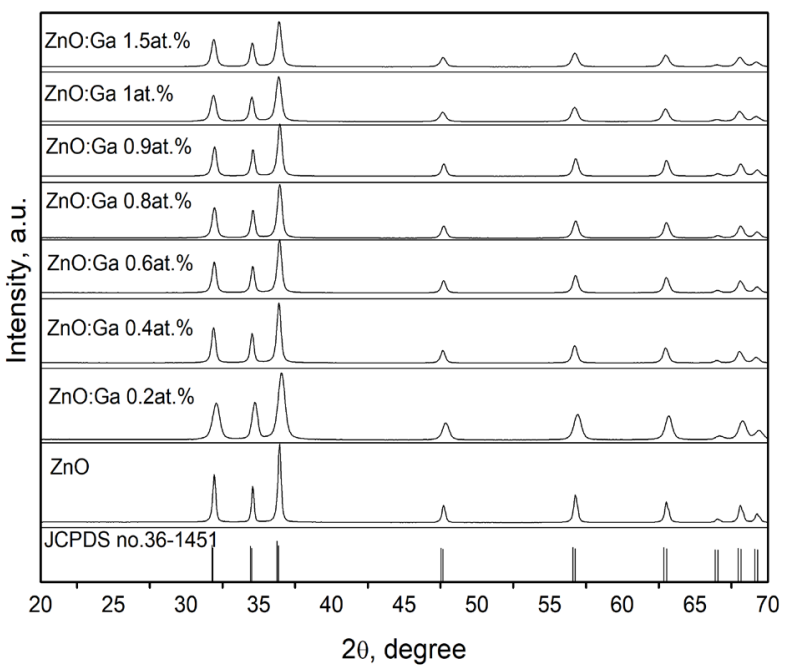

Fig. 2. X-ray powder diffraction patterns for $\mathrm{ZnO}$ and $\mathrm{ZnO}$ :Ga powders synthesized via MWST method.

\subsection{Analysis of SEM Results}

Figure 3 shows the morphology of the gallium-doped $\mathrm{ZnO}$ nanostructures. The samples appear to be heterogenic (partially due to the presence of gallium in sizeable amount). Particle sizes and shapes vary and asymmetrical units can be seen, which suggests partial agglomeration of particles. XRD data showed much smaller crystallite size ( $\sim 10$ times), but the method itself showed the size of individual crystallites. SEM image showed that, due to the agglomeration, there might be polycrystalline grains with different orientations and sizes. The dominant shape appears to be in the form of small nano-rice; there are some particle with greater length, which is due to the polar structure of $\mathrm{ZnO}$ and its growth along c-axis.

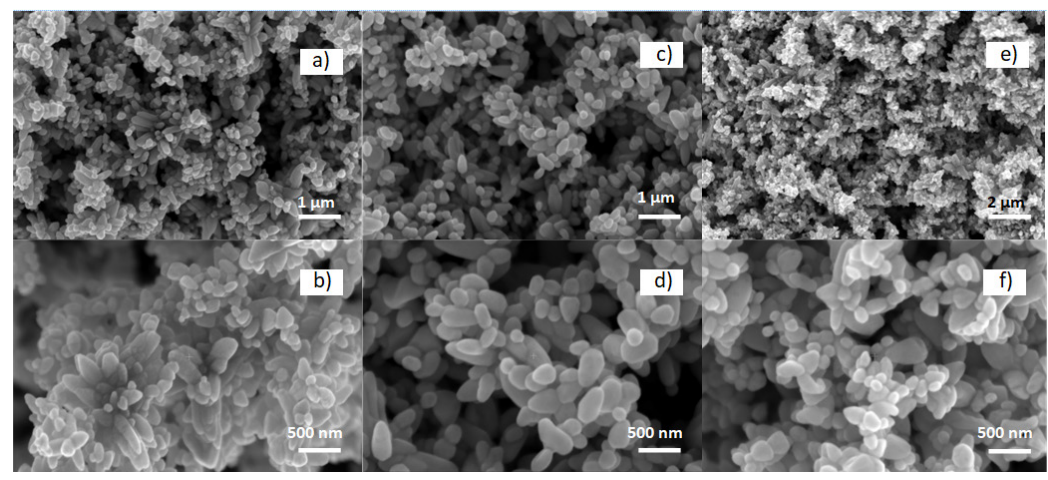

Fig.3. SEM images of ZnO:Ga 0.6 at.\% (a,b), ZnO:Ga 0.9 at.\% (c, d); ZnO:Ga 1.5 at.\% (e,f). 


\subsection{Luminescence Properties}

To compare and study optical properties of samples, powders were fixed in identical holders as well as the placement conditions were the same for all the samples. The repeatability was tested using the same powder fixed in 3 holders; the interchange of these holders showed that the peak posi- tions in luminescence spectra were strongly the same in all cases. The luminescence intensities were reproduced within $10 \%$; however, the NBL intensity relative to defect luminescence intensity was preserved in all spectra.

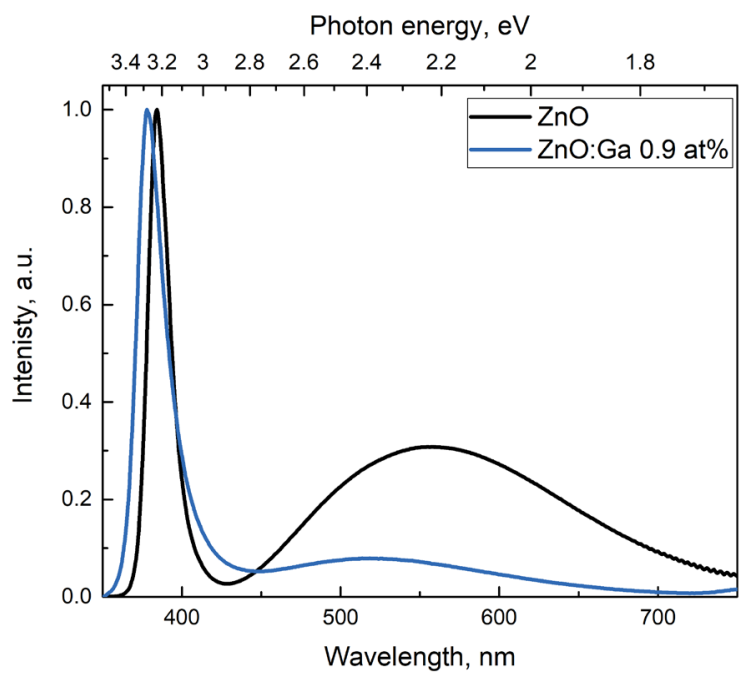

Fig. 4. Comparison of PL spectra of undoped and doped $\mathrm{ZnO}$.

Figure 4 shows room temperature PL spectra of $\mathrm{ZnO}$ and $\mathrm{ZnO}: \mathrm{Ga}$ with 0.9 at $\%$. The spectrum has two main emission bands: a relatively narrow NBL peak and a broad band centred around $550 \mathrm{~nm}$ that is attributed to defects in the lattice. The NBL peak positions slightly differ as well as its FWHM. NBL peak position of undoped $\mathrm{ZnO}$ is at $384 \mathrm{~nm}$ and it is shifted to long wave side. NBL peak position of $\mathrm{ZnO}: \mathrm{Ga}$ is at $379 \mathrm{~nm}$. It might be due to a wider band gap of $\mathrm{ZnO}: \mathrm{Ga}$ [20]. The changes in defect luminescence band maximum position could be associated with different luminescence centre contribution to emission. In turn, the relative defect luminescence contribution to undoped $\mathrm{ZnO}$ is larger than that for $\mathrm{ZnO}: \mathrm{Ga}$. Since the $\mathrm{ZnO}$ defect lumines- cence is undesirable for scintillators, the main study focuses on gallium-doped $\mathrm{ZnO}$ samples.

Figure 5 shows the photoluminescence spectra for several gallium-doped $\mathrm{ZnO}$ samples excited by $266 \mathrm{~nm}$ at RT. The spectra exhibit a strong near-band luminesce (NBL) between 377 and $382 \mathrm{~nm}$ and a minor peak around $550 \mathrm{~nm}$ in the green spectral region, which is also known as defect luminescence. One can see that $\mathrm{ZnO}$ doping with Ga results not only in the change of intensities of both NBL and defect luminescence but also in relative luminescence intensity. However, it is difficult to determine the best composition for a scintillator from Fig. 5. Therefore, Fig. 6 shows the normalized luminescence spectra. 


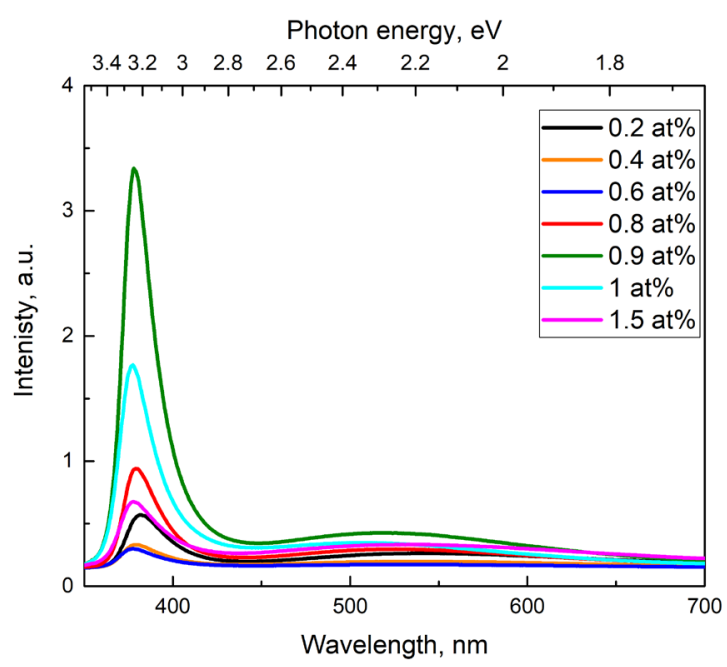

Fig. 5. Photoluminescence spectra of $\mathrm{ZnO}: \mathrm{Ga}$ with different gallium concentration excited by $266 \mathrm{~nm}$.

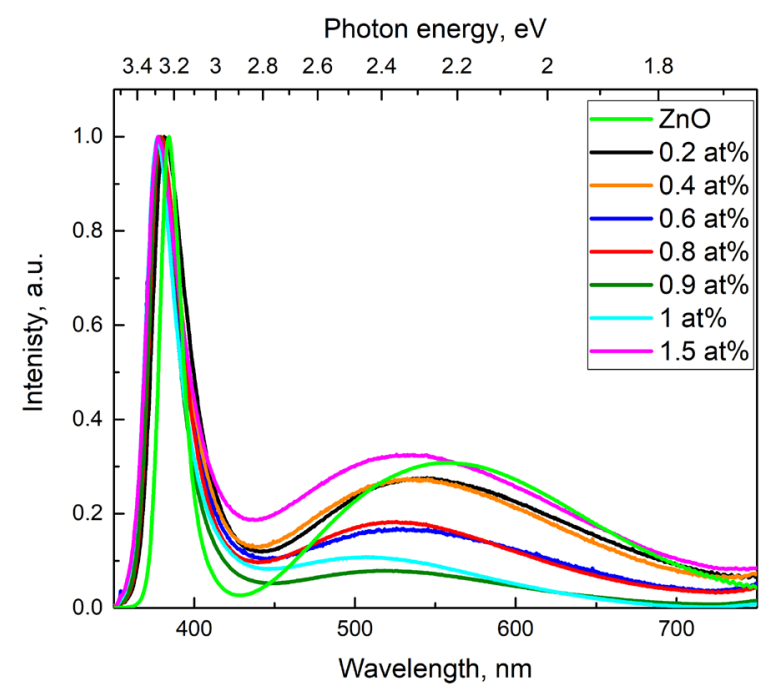

Fig. 6. Normalized photoluminescence spectra of $\mathrm{ZnO}$ and $\mathrm{ZnO}$ :Ga with different gallium concentration excited by $266 \mathrm{~nm}$.

Figure 6 shows the comparison between luminescence intensity of multiple samples; $\mathrm{ZnO}: \mathrm{Ga}$ with 0.9 at $\%$ displays the relatively low PL intensity in the defect band. The normalized PL spectra clearly show that defect luminescence intensity depends on gallium concentration. Figure 7 illustrates the dependence of the ratio of NBL and defect luminescence intensity $\left(\mathrm{I}_{\mathrm{NBL}} /\right.$ $I_{\text {def }}$ ). Optimal concentration of gallium was determined based on the comparison of
NBL peak intensity with defect band luminescence peak intensity. In Fig. 7, the best ratio of NBL intensity and defect luminescence intensity corresponds to 0.9 at $\%$ gallium concentration. The error bars are $10 \%$ of result as it could be associated with measurement error to experimentally confirm that samples were synthesized several times and results were repeatable and did not vary more than $10 \%$. 


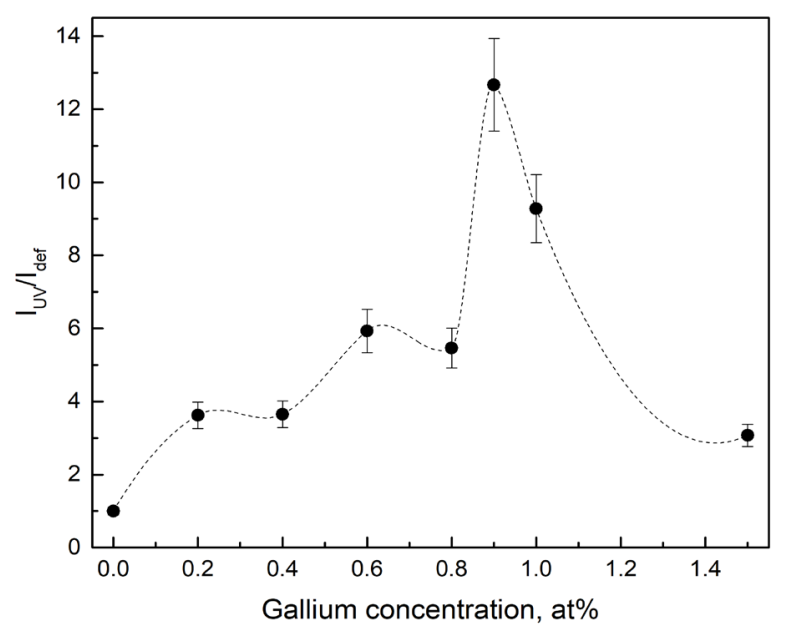

Fig. 7. Optimisation of gallium concentration in $\mathrm{ZnO}$ :Ga.

In Fig. 5, it can be observed that NBL tion on Ga concentration. The increased peak position slightly differs; Figure 8 concentration results in the peak shift to shows the dependence of NBL peak posi- shorter wavelengths.

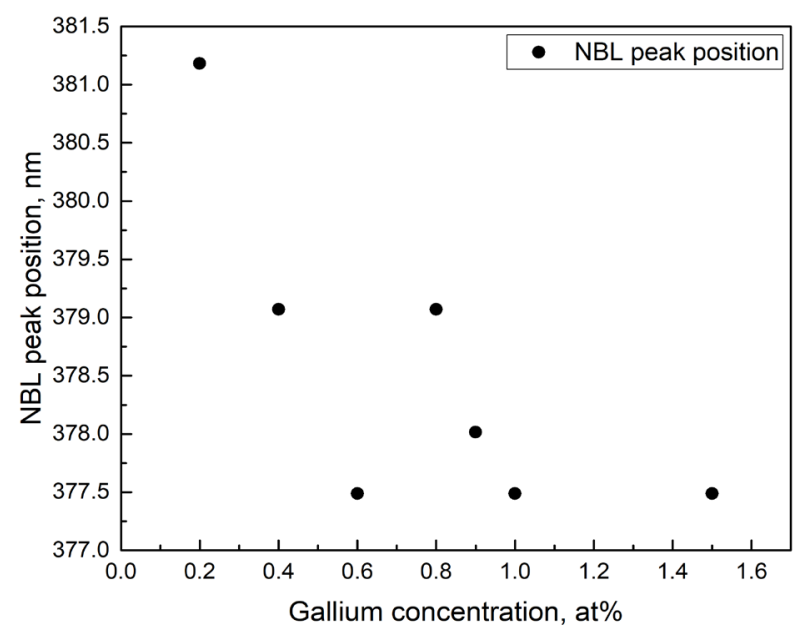

Fig. 8. NBL peak position in PL spectra of $\mathrm{ZnO}$ and $\mathrm{ZnO}$ : Ga samples.

The study of single crystal NBL luminescence at low temperature showed that there were up to 6 luminescence bands [4]. At RT in NBL, there could be either a free exciton 1 LO phonon replica (Ex1LO), or donor-acceptor pair (DA) luminescence. Intensity of free exciton phonon replicas luminescence of undoped $\mathrm{ZnO}$ is strongly reduced at $150 \mathrm{~K}$ and position of peak is very close to that for DA [21]. Therefore, the main contribution in NBL at $300 \mathrm{~K}$ is from DA. It is known that $\mathrm{Ga}$ acts as a donor in $\mathrm{ZnO}$ [4] and the peak position of DA luminescence depends on donor and acceptor mutual interaction [22], in other words, on donor-acceptor spatial distribution. There is another possibility that change in the NBL peak position could be associated with a shift of fundamental absorption edge [23]. However, the strong dependence of NBL 
on $\mathrm{Ga}$ concentration confirms that a donor is involved in the processes responsible for this luminescence.

The change in the defect luminescence band position and shape (Fig. 6) is also noted. These changes demonstrate possible gallium interactions with intrinsic defects in
$\mathrm{ZnO}$. Since the intrinsic defect concentration in $\mathrm{ZnO}$ is estimated to be at least $10^{18}$ $\mathrm{cm}^{-3}$ [21], even the dopant concentration of 0.2 at $\%$ could affect defect luminescence. Large dopant concentration could introduce additional defects necessary for charge compensation.

\section{CONCLUSION}

Gallium-doped $\mathrm{ZnO}$ powders prepared using a micro-wave assisted solvothermal method have wurzite structure and photoluminescence spectra of undoped $\mathrm{ZnO}$ and $\mathrm{ZnO}: \mathrm{Ga}$ samples with concentrations between 0.2 at $\%$ and 1.5 at $\%$ reveal that near-band luminescence peaking is close to $380 \mathrm{~nm}$ and defect luminescence band peak is within the range of approximately 510$550 \mathrm{~nm}$. ZnO:Ga displays an intensive NBL band and a suppressed defect luminescence band, which demonstrates excellent properties for applications in ionizing radiation detectors. Gallium concentration of 0.9 at $\%$ presents a relatively very low defect band and high near-band luminescence intensity, which make it a promising candidate for scintillators. This study is also beneficial to understand the influence of gallium concentration on zinc oxide morphology and luminescence properties.

\section{ACKNOWLEDGEMENTS}

The research has been supported by projectERA.NETRUS_ST2017-05 (Latvia) and No. 18-52-76002 (Russia). The Institute of Solid State Physics, University of Latvia as the Centre of Excellence has received funding from the European Union's Horizon 2020 Framework Programme H2020WIDESPREAD-01-2016-2017-TeamingPhase 2 under grant agreement No. 739508, project CAMART2 ${ }^{2}$.

\section{REFERENCES}

1. Janotti, A., \& van de Walle, C. G. (2009). Fundamentals of Zinc Oxide as a Semiconductor. Reports on Progress in Physics, 72 (12). https://doi.org/10.1088/0034-4885/72/ 12/126501

2. Moezzi, A., McDonagh, A. M., \& Cortie, M. B. (2012). Zinc Oxide Particles: Synthesis, Properties and Applications. Chemical Engineering Journal, 185-186, 1-22. https://doi.org/10.1016/j.cej.2012.01.076
3. Mondal, P. (2019). Effect of Oxygen Vacancy Induced Defect on the Optical Emission and Excitonic Lifetime of Intrinsic ZnO. Optical Materials, 98 (August), 109476. https://doi. org/10.1016/j.optmat.2019.109476

4. Özgür, Ü., Alivov, Y. I., Liu, C., Teke, A., Reshchikov, M. A. ... \& Morkọ, H. (2005). A comprehensive Review of ZnO Materials and Devices. Journal of Applied Physics, 98 (4), 1-103. https://doi.org/10.1063/ 1.1992666 
5. Procházková, L., Gbur, T., Čuba, V., Jarý, V., \& Nikl, M. (2015). Fabrication of Highly Efficient $\mathrm{ZnO}$ Nanoscintillators. Optical Materials, 47, 67-71. https://doi. org/10.1016/j.optmat.2015.07.001

6. Wang, Z., Nayak, P. K., CaraveoFrescas, J. A., \& Alshareef, H. N. (2016). Recent Developments in p-Type Oxide Semiconductor Materials and Devices. Advanced Materials, 28 (20), 3831-3892. https://doi.org/10.1002/adma.201503080

7. Angub, M. C. M., Vergara, C. J. T., Husay, H. A. F., Salvador, A. A., Empizo, M. J. F. ... \& Somintac, A. S. (2018). Hydrothermal Growth of Vertically Aligned $\mathrm{ZnO}$ Nanorods as Potential Scintillator Materials for Radiation Detectors. Journal of Luminescence, 203, 427-435. https://doi. org/10.1016/j.jlumin.2018.05.062

8. Sato, E., Sugimura, S., Endo, H., Oda, Y., Abudurexiti, A. .. \& Onagawa, J. (2012). 15Mcps Photon-Counting X-ray Computed Tomography System Using a ZnO-MPPC Detector and its Application to Gadolinium Imaging. Applied Radiation and Isotopes, 70 (1), 336-340. https://doi.org/10.1016/j. apradiso.2011.07.002

9. Sato, E., Matsukiyo, H., Osawa, A., Enomoto, T., Watanabe, M. ... \& Sato, S. (2008). X-ray Computed Tomography System Using a Multipixel Photon Counter. Hard X-Ray, Gamma-Ray, and Neutron Detector Physics X, 7079(2008), 70790H. https://doi.org/10.1117/12.795434

10. Derenzo, S. E., Weber, M. J., BourretCourchesne, E., \& Klintenberg, M. K. (2003). The Quest for the Ideal Inorganic Scintillator. Nuclear Instruments and Methods in Physics Research, Section A: Accelerators, Spectrometers, Detectors and Associated Equipment, 505 (1-2), 111-117. https://doi.org/10.1016/S01689002(03)01031-3

11. Grigorjeva, L., Millers, D., Smits, K., Grabis, J., Fidelus, J. ... \& Bienkowski, K. (2010). The Luminescence of $\mathrm{ZnO}$ Ceramics. Radiation Measurements, 45 (3-6), 441-443. https://doi.org/10.1016/j. radmeas.2010.03.012
12. Li, Q., Liu, X., Gu, M., Huang, S., Zhang, J. ... \& Zhao, S. (2016). X-ray Excited Luminescence of Ga- and In-doped $\mathrm{ZnO}$ Microrods by Annealing Treatment. Superlattices and Microstructures, 98, 351358. https://doi.org/10.1016/j.spmi.2016.09. 005

13. Kano, M., Wakamiya, A., Sakai, K., Yamanoi, K., Cadatal-Raduban, M. ... \& Fukuda, T. (2011). Response-TimeImproved $\mathrm{ZnO}$ Scintillator by Impurity Doping. Journal of Crystal Growth, 318 (1), 788-790. https://doi.org/10.1016/j. jcrysgro.2010.10.192

14. Demidenko, V. A., Gorokhova, E. I., Khodyuk, I. v., Khristich, O. A., Mikhrin, S. B., \& Rodnyi, P. A. (2007). Scintillation Properties of Ceramics Based on Zinc Oxide. Radiation Measurements, 42 (4-5), 549-552. https://doi.org/10.1016/j.radmeas. 2007.01.050

15. al Abdullah, K., Awad, S., Zaraket, J., \& Salame, C. (2017). Synthesis of $\mathrm{ZnO}$ Nanopowders by Using Sol-Gel and Studying their Structural and Electrical Properties at Different Temperature. Energy Procedia, 119, 565-570. https://doi. org/10.1016/j.egypro.2017.07.080

16. Khoshhesab, Z. M., Sarfaraz, M., \& Asadabad, M. A. (2011). Preparation of $\mathrm{ZnO}$ Nanostructures by Chemical Precipitation Method. Synthesis and Reactivity in Inorganic, Metal-Organic and Nano-Metal Chemistry, 41 (7), 814-819. https://doi.org/ 10.1080/15533174.2011.591308

17. Ghoshal, T., Biswas, S., Paul, M., \& De, S. K. (2009). Synthesis of ZnO Nanoparticles by Solvothermal Method and their Ammonia Sensing Properties. Journal of Nanoscience and Nanotechnology, 9 (10), 5973-5980. https://doi.org/10.1166/jnn.2009.1290

18. Thamima, M., \& Karuppuchamy, S. (2015). Microwave Assisted Synthesis of Zinc Oxide Nanoparticles. International Journal of ChemTech Research, 8 (11), 250-256. https://doi.org/10.1016/j.mspro.2015.11. 101 
19. Jayathilake, D. S. Y., Peiris, T. A. N., Sagu, J. S., Potter, D. B., Wijayantha, K. G. U. ... \& Southee, D. J. (2017). MicrowaveAssisted Synthesis and Processing of AlDoped, Ga-Doped, and Al, Ga Codoped $\mathrm{ZnO}$ for the Pursuit of Optimal Conductivity for Transparent Conducting Film Fabrication. ACS Sustainable Chemistry and Engineering, 5 (6), 4820-4829. https:// doi.org/10.1021/acssuschemeng.7b00263

20. Makino, T., Segawa, Y., Yoshida, S., Tsukazaki, A., Ohtomo, A., \& Kawasaki, M. (2004). Gallium Concentration Dependence of Room-Temperature Near-Band-Edge Luminescence in n-Type $\mathrm{ZnO}: \mathrm{Ga}$. Applied Physics Letters, 85 (5), 759-761. https:// doi.org/10.1063/1.1776630

21. Meyer, B. K., Alves, H., Hofmann, D. M., Kriegseis, W., Forster, D. ... \& Rodina, A. V. (2004). Bound Exciton and Donor-Acceptor Pair Recombinations in ZnO. Physica Status Solidi (B) Basic Research, 241 (2), 231-260. https://doi. org/10.1002/pssb.200301962
22. Kotomin, E. A., \& Doktorov, A. B. (1982). Theory of Tunneling Recombination of Defects Stimulated by their Motion II. Three Recombination Mechanisms. Physica Status Solidi (B), 114 (2), 287-318. https:// doi.org/10.1002/pssb.2221140202

23. Kim, J., Naik, G. V., Gavrilenko, A. V., Dondapati, K., Gavrilenko, V. I. ... \& Boltasseva, A. (2014). Optical Properties of Gallium-Doped Zinc Oxide - A LowLoss Plasmonic Material: First-Principles Theory and Experiment. Physical Review X, 3 (4), 1-9. https://doi.org/10.1103/ PhysRevX.3.041 